\title{
IMPLANTAÇÃO DE UM MODELO SUSTENTADO DE ENSINO HÍBRIDO EM MATEMÁTICA BASEADO NA PROPOSTA DE UM QUADRO ADAPTATIVO
}

\section{IMPLANTATION OF A SUSTAINED BLENDED LEARNING MODEL IN MATHEMATICS BASED ON THE PROPOSAL OF AN ADAPTIVE FRAMEWORK}

\section{Geraldo Henrique Alves Pereira}

Instituto Federal de Educação, Ciência e Tecnologia de Minas Gerais (IFMG) - Campus Bambuí, Universidade Cruzeiro do Sul (Unicsul), geraldo.pereira@ifmg.edu.br

\section{Juliano Schimiguel}

Professor Permanente do Programa de Doutorado/Mestrado em Ensino de Ciências e Matemática, Universidade Cruzeiro do Sul (Unicsul), Rua Galvão Bueno, 868, Campus Liberdade, São Paulo/SP, juliano.schimiguel@cruzeirodosul.edu.br

\section{Resumo}

Este artigo aborda um tema em evidência em ensino de Matemática: a inserção de tecnologias na sala de aula e sua interseção com as propostas de Ensino Híbrido. A questão norteadora fundamenta-se na pergunta: quais referências práticas exitosas podem ser consideradas para se implementar primeiras experiências de Ensino Híbrido? A partir disso, este texto encontra justificativa diante da ausência de instruções e capacitação sobre a aplicação de experiências de Ensino Híbrido e da carência de estudos que detalhem o emprego de atividades deste modelo. Neste cenário, objetivou-se criar um quadro adaptativo que forneça a professores interessados no tema subsídios para implementar experiências iniciais de Ensino Híbrido em aulas de Matemática. Partindo de uma metodologia comparativa de conteúdos de três estudos selecionados, foram apresentados os resultados a partir dos indicativos feitos, de forma que compusessem as primeiras interpretações dos processos híbridos relatados e, como proposto, servissem de referência para o quadro adaptativo que se construiu ao final da quarta seção. Por fim, apontaram-se considerações no intuito de reforçar a proeminência do debate envolvendo tecnologias e ensino, determinando implicações no papel docente a partir dos cenários e perspectivas do Ensino Híbrido nessa nova realidade tecnológica.

Palavras-chave: Tecnologias. Ensino Híbrido. Modelo sustentado. Matemática.

\section{Abstract}

This article discuss an outstanding theme in Mathematics teaching: the insertion of technologies in the classroom and its intersection with the proposals of Blended Learning. The guiding question is based on the question: which successful practical references can be considered to implement first Blended Learning experiences? From this, this text finds justification in the absence of instructions and training on the application of Blended Learning experiences and the lack of studies that detail the use of the activities of this model. In this scenario, the objective was to create an adaptive framework that will provide teachers interested in the theme with the necessary subsidies to implement initial Blended Learning 
experiences in Mathematics classes. Starting from a comparative methodology of contents of three selected studies, were presented the results from the indicative ones made in such a way as to compose the first interpretations of the hybrid processes reported and, as proposed, serve as reference for the adaptive framework that was constructed at the end of the fourth section. Finally, considerations were made with the intention of reinforcing the prominence of the debate involving technologies and teaching, determining out implications in the teaching role from the scenarios and perspectives of Blended Learning in this new technological reality.

Keywords: Technologies. Blended Learning. Sustained model. Mathematics.

\section{Introdução}

O tema abordado neste artigo vem ao encontro de uma importante corrente de pesquisa na área de ensino, inclusive na Educação Matemática: a implicação didáticometodológica que a inserção de tecnologias vem causando na prática profissional do professor, nos processos de aprendizagem do estudante e na organização e planejamento institucional das escolas.

A ampliação e a popularização das tecnologias móveis experimentadas nos últimos anos, sobretudo daquelas associadas à Internet, desenham um cenário de múltiplas possibilidades para os processos de ensino. Segundo a Organização das Nações Unidas para a Educação, a Ciência e a Cultura (Unesco, 2014), este fato impulsionou sobremaneira a propagação da Educação a Distância (EaD), que, nos últimos anos, é uma realidade cada vez mais próxima da escola regular, que, por sua vez, parece resistir, não de maneira generalizada, obviamente, mas de modo bastante significativo. E o motivo dessa resistência encontra-se naquele que está à frente do ensino: o professor.

Entretanto, há casos de suplantação do modelo tradicional de ensino para a experimentação de situações novas, metodologicamente ligadas às tecnologias. Este artigo mostrará que a apropriação das tecnologias da EaD pelos cursos em formatos presenciais, em quaisquer níveis de ensino, tem se configurado como parte da estrutura básica das teorizações acerca do que se tem chamado de Ensino Híbrido, ou Blended Learning. A denotação dada ao termo Ensino Híbrido será apresentada com a ênfase necessária na seção seguinte. Todavia, desde já, grafa-se que a mistura anunciada pelo termo está nas mídias e nas metodologias utilizadas no ensino. Essa mistura, oriunda de primeiras experiências de e-learning, como a EaD, pressupõe a inserção de tecnologias digitais no processo de aprendizagem, sendo capaz de incrementar a sala de aula e remodelar alguns de seus instrumentos.

Além dos estudos utilizados como parâmetros para a comparação que, adiante, este artigo apresentará, as próprias experiências profissionais de prática de sala de aula e de pesquisa dos autores deste artigo complementam o arcabouço teórico que motivou 0 presente estudo. Isso indica, por consequência, que há uma questão de investigação maior, propulsora desta pesquisa: quais referências práticas exitosas podem ser consideradas para se implementar primeiras experiências de ensino híbrido?

Partindo desse pressuposto, este texto encontra justificativa diante da ausência de instruções e capacitação - em nível de formação inicial ou continuada - sobre a aplicação de experiências de Ensino Híbrido e da carência de estudos que detalhem o emprego de atividades deste modelo, conforme será demonstrado nos processos metodológicos descritos 
na seção 3. Desse modo, torna-se relevante a publicação deste texto, que primeiro estuda, analisa e compara outros estudos, para, depois, juntá-los numa espécie de tutorial para auxiliar quem pretende conhecer mais sobre esse assunto.

Partindo de comparações entre três estudos distintos, o objetivo geral deste trabalho é criar um quadro adaptativo que forneça a possíveis professores interessados subsídios para implementar primeiras experiências de Ensino Híbrido em aulas de Matemática. Ademais, de forma específica, também se objetivou estabelecer uma discussão teórica sobre diferentes modelos desse tema, captar elementos provenientes de relatos de experiências que, juntos, consigam formar indicativos para implementar outras experiências de ensino com reduzido grau de incerteza e, também, subsidiar teoricamente estudos iniciais de outros profissionais do ensino.

$\mathrm{Na}$ seção seguinte, registra-se um referencial teórico consistente, que condensa vertentes diferentes de alinhamento teórico nas abordagens e definições do tema, além de respaldar um bom início de discussão para as implicações que as tecnologias trarão para a escola num futuro próximo.

$\mathrm{Na}$ terceira seção, os aspectos metodológicos da pesquisa foram registrados, dando ênfase aos critérios adotados no processo de seleção e à forma de comparação dos estudos selecionados.

Já na quarta seção, apresentaram-se os resultados e os indicativos dos estudos selecionados, de forma tal que compusessem as primeiras interpretações dos processos híbridos relatados e, como proposto, servissem de referência para o quadro adaptativo que se pretendeu construir na última subseção.

Por fim, na quinta seção, constam considerações finais depreendidas do processo de pesquisa e análise em tela, tendo como propósito uma reflexão crítica sobre o que se buscou registrar.

Antes de passar à próxima seção, é preciso destacar uma variação no tratamento de alguns termos provenientes das próprias referências utilizadas. Desta forma, estar-se-á falando da mesma coisa sempre que forem utilizados os termos Rotação por Sala de Aula Invertida e Sala de Aula Invertida, assim como quando utilizados Rotação por Estações de Trabalho e Rotação por Estações.

\section{Referencial teórico}

O Ensino Híbrido é consequência de uma discussão que se instaurou há, pelo menos, duas décadas nas pesquisas acadêmicas nacionais e internacionais da área de ensino: a utilização de tecnologias digitais ${ }^{1}$ na sala de aula.

Em 2004, o professor José Manuel Moran já buscava registrar algumas das competências que o professor de cursos presenciais precisava adquirir ou se capacitar. Para ele, era premente que este profissional, para educar com qualidade, aprendesse a gerenciar vários espaços e integrá-los de forma aberta, equilibrada e inovadora em, pelo menos, quatro ambientes: uma nova sala de aula (equipada e conectada), um laboratório conectado, ambientes virtuais de aprendizagem e ambientes experimentais e profissionais (MORAN,

\footnotetext{
1 Neste estudo, considerou-se, na maior parte das menções, apenas o termo tecnologias para designar todas aquelas que se encaixam, na atualidade, ao espectro digital.
} 
O primeiro espaço é o de uma nova sala de aula equipada e com atividades diferentes, que se integra com a ida ao laboratório para desenvolver atividades de pesquisa e de domínio técnico-pedagógico. Estas atividades se ampliam e complementam a distância, nos ambientes virtuais de aprendizagem e se complementam com espaços e tempos de experimentação, de conhecimento da realidade, de inserção em ambientes profissionais e informais. (MORAN, 2004, p. 2).

Não há, neste texto de Moran (2004), a menção explícita do termo ou mesmo da concepção do Ensino Híbrido; mas se percebe claramente que suas bases já estão criadas e anunciadas.

O estudo de Peña e Allegretti (2012) discute uma tendência desse período: o barateamento da tecnologia, a facilidade de aceso à Internet, a convergência de mídias, a comunicação entre os jovens e a instalação de uma cultura digital, que vêm transformando fortemente as relações entre as pessoas, especialmente os jovens, que, sob condições naturais, estão constantemente conectados. As autoras também reforçam a configuração híbrida que a atual sociedade detém e a capacidade que os dispositivos midiáticos que permeiam esta sociedade têm de permitir a imersão em ambientes virtuais - fato que amplia significativamente as potencialidades de aprendizagem dos sujeitos envolvidos a partir da criação, da vivência e do acesso a informações diversificadas.

Ainda para estas autoras, por uma questão de sobrevivência, a hibridização da escola, tal como a sociedade moderna, é uma questão urgente. Neste sentido, é preciso

romper com o espaço "aula convencional" e permitir que o professor e os alunos extraiam dos ambientes virtuais de aprendizagem e dos dispositivos midiáticos interativos e imersivos toda a sua potencialidade para a aprendizagem em tempo real, ou seja, durante a aula presencial (PEÑA; ALLEGRETTI, 2012, p. 103).

Um estudo da Unesco (2014) registra que, mesmo com as mudanças ocasionadas em nossa vida pelas 5,9 bilhões de assinaturas de telefone celular em todo o mundo (em 2014), os educadores e formuladores de políticas não têm conseguido aproveitar plenamente seu potencial para melhorar o aprendizado.

Neste cenário, os avanços tecnológicos dessas últimas duas décadas, principalmente o horizonte das próximas, "requerem novas metodologias de ensino, as quais necessitam de novos suportes pedagógicos, transformando o papel do professor e dos estudantes e ressignificando o conceito de ensino e aprendizagem". Nesse sentido, o ensino online permite tal personalização, oferecendo o modelo híbrido como alternativa para preencher essas lacunas do processo de aprendizagem (BACICH; TANZI NETO; TREVIZANI, 2015, p. 51).

Para Moran (2015b, p. 39), o "professor precisa seguir comunicando-se face a face com os alunos, mas também digitalmente, com as tecnologias móveis, equilibrando a interação com todos e com cada um".

Este estudo não pretende discorrer longamente sobre os diferentes conceitos dados ao Ensino Híbrido. Para além das várias teorizações e vertentes, ele se cinge na adoção daquele que talvez seja o conceito-gênese: 
O ensino híbrido é um programa de educação formal no qual um aluno aprende, pelo menos em parte, por meio do ensino online, com algum elemento de controle do estudante sobre o tempo, lugar, modo e/ou ritmo do estudo, e pelo menos em parte em uma localidade física supervisionada, fora de sua residência (CHRISTENSEN; HORN; STAKER, 2013, p. 7).

Também, como complemento, este estudo apoiar-se-á no esquema dado pela Figura 1, para representar os modelos de possibilidades de aplicação da teoria:

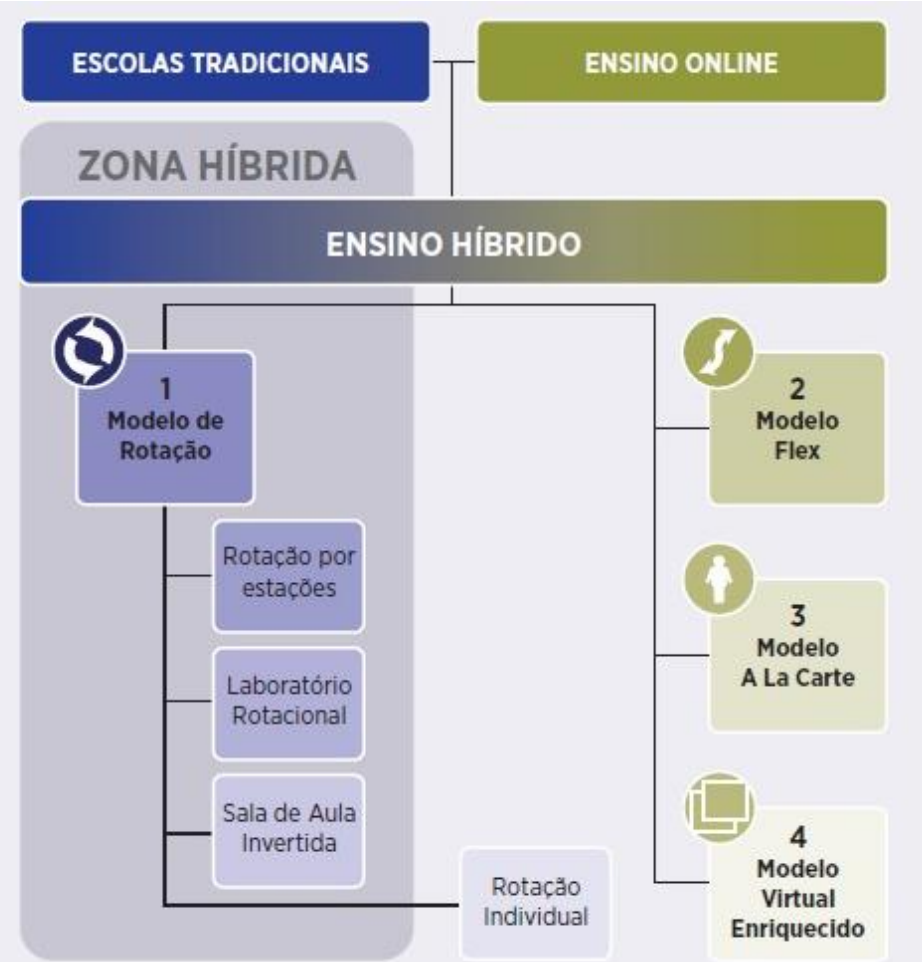

Figura 1 - Caraterização do Ensino Híbrido por Christensen, Horn e Staker (2013) Fonte: Christensen, Horn e Staker (2013, p. 28)

Naturalmente, há diferentes entendimentos em relação aos modelos de Ensino Híbrido. Moran (2015b) e Costa (2016), por exemplo, consideram a Sala de Aula Invertida um modelo à parte do Ensino Híbrido, sendo este último um exemplo de modelo não disruptivo. Por outro lado, há autores que argumentam que, por definição, a educação sempre foi misturada. Para Moskal, Dziubian e Hartman (2013), isso pode até fazer sentido, mas a escala de impacto e o grau de qualidade possibilitada atualmente nunca antes foram oferecidos.

Há, também, formas de entender o Ensino Híbrido numa visão mais holística, não se restringindo apenas às mídias e metodologias utilizadas para a aprendizagem. Moran (2015a), por exemplo, preceitua que "o ensino híbrido não se reduz a metodologias ativas, ao mix de presencial e on-line, de sala de aula e outros espaços". Já Filipe e Orvalho (2004, p. 217) registram que ele "é muito mais do que uma multiplicação de canais, é uma combinação de métodos de ensino/aprendizagem".

Nesta mesma acepção, Bacich, Tanzi Neto e Trevisani (2015, p. 51-52) indicam:

O ensino híbrido, da maneira que vem sendo utilizado em escolas de educação básica nos Estados Unidos, na América Latina e na Europa, difere das definições de blended learning voltadas para o ensino 
superior e entendidas como aquele modelo em que o método tradicional, presencial, se mistura com o ensino a distância e, em alguns casos, determinadas disciplinas são ministradas na forma presencial, enquanto, outras, apenas on-line. Esse seria o uso original do termo, que evoluiu para abarcar um conjunto muito mais rico de estratégias ou dimensões de aprendizagem [...]. A expressão ensino híbrido está enraizada em uma ideia de educação híbrida, em que não existe uma forma única de aprender e na qual a aprendizagem é um processo contínuo, que ocorre de diferentes formas, em diferentes espaços.

Ressalta-se a convergência de modelos de aprendizagem em quaisquer das interpretações dadas. Nelas, o modelo tradicional, que ocorre na sala de aula, e o modelo virtual vão se misturar para promover o ensino, tornando-se, gradativamente, complementares. Desse modo, pela combinação metodológica, os papéis desempenhados por professor e alunos sofrem alterações em relação à proposta de ensino considerado tradicional, e as configurações das aulas favorecem momentos de interação, colaboração e envolvimento com as tecnologias digitais (BACICH; TANZI NETO; TREVIZANI, 2015).

A inserção de tecnologias nas salas de aula, sob uma perspectiva de Ensino Híbrido, pressupõe também o incentivo permanente à autonomia do discente, de forma que ele seja capaz não só de escolher os melhores momentos para estudo, mas também as fontes necessárias (CASTRO et al., 2015).

Tudo isso significa dizer que a simples utilização de tecnologias digitais em sala de aula, seja pelo professor ou pelos estudantes, não se configura, a partir da maioria dos estudos na área, como uma atividade de Ensino Híbrido. Em outras palavras, pode-se dizer que, para ser híbrida, uma experiência de ensino precisa criar uma rede de aprendizagem, com características formais e informais, mediada, obrigatoriamente, por ambientes online (CASTRO et al., 2015).

Para Costa (2016), a simples associação de tecnologias ou de um ambiente virtual ao contexto presencial não representa um modelo de Ensino Híbrido. Neste caso, há uma extensão da carga horária do curso presencial, e o professor, à sua maneira, restringe o que é de cada espaço. Sob análise parecida, Peña e Allegretti (2012, p. 103) reforçam que os ambientes virtuais não devem simplesmente reproduzir aquilo que já se faz no ambiente físico, ou seja, virtualizar o tradicional espaço físico - é preciso "desencadear a cultura da colaboração".

Assim sendo, as tecnologias e os dispositivos móveis serviriam, por este modo de ver o Ensino Híbrido, para integrar espaços formais e informais de aprendizagem. Essa conexão poderia ser considerada como o que alguns estudiosos já chamam de aprendizagem contínua, ou seja, desenvolvida sem a ruptura de espaços, ambientes, tempo, sujeitos etc.

No entanto, as experiências mostram sucessos e fracassos, naturalmente. De forma geral, iniciativas de Ensino Híbrido do tipo BYOD (Traga o Seu Próprio Dispositivo, no inglês Bring Your Own) mostraram-se exitosas. Todavia, a pressão adicional por largura de banda de Internet e a oferta de subsídios para compra de dispositivos aos alunos menos favorecidos economicamente revelaram-se fatores críticos para sua implementação (UNESCO, 2014), sendo também, atualmente, um sinal de alerta para qualquer início de discussão.

Outro problema facilmente detectado é a frágil autorresponsabilidade de alguns alunos em empreender trabalhos autônomos dentro dos períodos estabelecidos e dos objetivos 
propostos para as disciplinas (FILIPE; ORVALHO, 2004). Ademais, para Castro et al. (2015, p. 48), "alunos e professores precisam familiarizar-se com as tecnologias existentes e desenvolver a capacidade de manipular, interagir e produzir conteúdo dentro do ambiente virtual para que as atividades interativas on line tenham sucesso".

Por fim, do relatório da Unesco (2014), extraiu-se um delineamento de itens que indicam alguns dos avanços tecnológicos dos próximos anos com maior probabilidade de impactar o ensino e o aprendizado, partindo de uma perspectiva global:

(i) A tecnologia será mais acessível, barata e funcional;

(ii) os dispositivos conseguirão coletar, sintetizar e analisar enormes quantidades de dados;

(iii) teremos à disposição novos tipos de dados;

(iv) as barreiras da linguagem serão superadas;

(v) as limitações impostas pelo tamanho da tela desaparecerão;

(vi) melhorias nas fontes de energia e no potencial energético dos aparelhos.

A partir disso, pretende-se neste estudo pôr à luz a necessária discussão do quão perto estão a escola e seus métodos das tecnologias que estarão nas mãos de seus estudantes num futuro bem próximo.

\section{Procedimentos metodológicos}

Neste artigo, a pesquisa realizada caracteriza-se, de acordo com as classificações propostas por Silva e Menezes (2001) e Prodanov e Freitas (2013), como qualitativa, do ponto de vista da abordagem do problema; bibliográfica, conforme os procedimentos técnicos adotados; exploratória, no enfoque de seus objetivos; e básica, do ponto de vista de sua natureza.

Diante do cenário construído para a pesquisa, a consecução dos seus propósitos foi buscada, inicialmente, pela pesquisa de material bibliográfico sobre o tema Ensino Híbrido, ou Blended Learning. Para isso, procedeu-se com uma pesquisa a partir desses termos nos principais sítios eletrônicos de busca, especialmente o Google Schoolar, e nos principais periódicos da área de ensino de Matemática². É preciso registrar que, neste último lócus de pesquisa, não foi encontrada nenhuma publicação, o que mostra, ainda que intuitivamente, a baixa produção de pesquisas nesta área acadêmica.

Do material selecionado, pretendeu-se separar aqueles que tratavam e discutiam relatos de experiências de Ensino Híbrido, em qualquer nível de ensino, com foco nos resultados captados no desenvolvimento dos estudantes. A priori, esperavam-se encontrar pesquisas desse tipo versando sobre o ensino de Matemática, mas, diante da ausência de artigos com essa abordagem, passou-se a considerar qualquer disciplina acadêmica. Os artigos que viessem a ser selecionados seriam objeto de análise sob um ponto de vista comparativo, sem, contudo, buscar contrapor os resultados obtidos em cada um, nem tampouco avaliar sua eficiência. Assim, a leitura do material visou à criação de um cenário amplo, em que os relatos das experiências pudessem, juntos, construir um quadro capaz de fornecer subsídios para que um professor interessado no tema consiga implementar, sempre com as devidas adaptações, uma experiência desse tipo em aulas da disciplina de Matemática. A esse esquema, deu-se o nome de quadro adaptativo.

${ }^{2}$ Avaliados com estratos Qualis A1, A2, B1 ou B2. 
Foram selecionados, portanto, três estudos que atendiam às modelações iniciais:

a) Torres et al. (2014): com o título "Implantação da metodologia híbrida (blended learning) de educação numa instituição de ensino privada" - o trabalho teve por objetivo analisar a implementação de disciplinas a distância num curso presencial de uma instituição privada de ensino. Apresentou experiência no ensino superior. Não deu uma caracterização específica para o tipo de modelo sustentado de Ensino Híbrido, mas, pela leitura do material, aproximou-se da Sala de Aula Invertida;

b) Andrade e Souza (2016): com o título "Modelos de Rotação no Ensino Híbrido: estações de trabalho e Sala de Aula Invertida" - o trabalho objetivou apresentar estudos de casos que abordam o conceito de Ensino Híbrido nesses dois modelos e engajar docentes para o planejamento de suas próprias experiências nesse tema. Apresentou experiências no ensino médio e fundamental. Utilizou precisamente os modelos que anuncia no título;

c) Schiehl e Gasparini (2016): com o título "Contribuições do Google Sala de Aula para o Ensino Híbrido", o trabalho visou discutir o modelo híbrido de ensino e apresentar o Google Sala de Aula. Apresentou experiência no ensino médio. Utilizou o modelo de Rotação por Estações.

Destaca-se o fato de os três estudos terem características distintas, não só pela abordagem que cada um deu aos modelos sustentados de Ensino Híbrido, mas também pelos níveis de ensino em que se concentram. Estes fatos corroboram para criar o cenário de comparação pretendido de forma mais abrangente e completa.

\section{Apresentação dos resultados}

Após a leitura do material selecionado, buscaram-se os principais pontos, confluentes ou complementares, que, juntos, poderiam formar um quadro com instruções para auxiliar na implementação de experiências de Ensino Híbrido em turmas da disciplina de Matemática. Este quadro, desde o princípio denominado quadro adaptativo, tem como principal função condensar reflexões e indicativos que, pretensamente, possam ajudar na formatação de experiências em diferentes realidades de escolas pelo País - daí, a necessidade da característica adaptativa.

Por isso, recorrendo à apresentação das diferentes possibilidades de execução das etapas de uma experiência de Ensino Híbrido tratadas no referencial teórico, adensadas com os resultados colhidos nos estudos analisados, indicados na metodologia, objetivou-se estruturar um material que possa servir de suporte para experimentações práticas futuras de professores de Matemática interessados no assunto em questão.

Nas subseções a seguir, o texto tratará individualmente de alguns pontos chamados à atenção nos três estudos utilizados e, ao fim de cada uma, apresentará indícios para o delineamento do quadro adaptativo estruturado na última subseção. Desta forma, a cada conjunto de informações retiradas dos textos de Torres et al. (2014), Andrade e Souza (2016) e Schiehl e Gasparini (2016), seguir-se-á uma discussão com caráter prático, que servirá de base para a apresentação do quadro final.

\subsection{Abordagens principais de Ensino Híbrido}


No estudo de Torres et al. (2014), foi adotado um modelo híbrido em disciplinas a distância, sem seguir as caracterizações específicas propostas por Christensen; Horn e Staker (2013). Contudo, pela descrição apresentada, aproxima-se do modelo de Sala de Aula Invertida. A maior parte do conteúdo das disciplinas foi transmitida a distância, com a produção de atividades presenciais.

Já no trabalho de Andrade e Souza (2016), são apresentados e discutidos dois modelos sustentados de Ensino Híbrido: Rotações por Estações de Trabalho (RET) e Rotação por Sala de Aula de Invertida (RSAI), conforme é detalhado a seguir:

RET: (i) Pelo menos uma estação deve se estruturar num contexto online. (ii) Há de se analisar o tamanho do grupo de estudantes versus o tempo em que ocorrerá a rotação. (iii) Utilizar o mínimo da estrutura da sala de aula tradicional. (iv) Propôs-se um grande número de estações para que cada grupo ficasse com um número menor de estudantes. RSAl: (i) A aprendizagem é mista e ocorre nos dois momentos. (ii) O aluno, com seu próprio ritmo, acessa o conteúdo online de acordo com sua programação, e não sob condições de toda a turma. (iii) Planejamento é aspecto crítico para sua implantação. (iv) Sugere-se, quando utilizados, a produção de vídeos curtos. (v) A seleção de conteúdos de qualidade e adequados ao nível do currículo dos alunos é essencial.

Schiehl e Gasparini (2016) exploram também o modelo de Ensino Híbrido denominado Rotação por Estações, destacando que ele possui aspectos de rupturas flexíveis ao modo de trabalho e não afeta a estrutura física existente. Para a implantação do modelo, sugere-se escolher estudantes-chave com facilidade na disciplina para ajudar os estudantes com dificuldades.

\section{Indícios para delineamento do quadro adaptativo}

Como se vê, pelos estudos explorados, um modelo de Ensino Híbrido sustentado busca amparo em dois modelos: Rotação por Estações (de Trabalho) e Sala de Aula Invertida - inevitavelmente, e por definição, com amparo de tecnologias.

O primeiro modelo, sob a percepção destes autores, vai demandar uma estrutura de preparação e planejamento maior, já que os estudantes necessitarão de maior liberdade pelas estações de trabalho/estudo, o que vai impactar diretamente numa postura ubíqua do professor. Esse fato, inclusive, dependendo do número de estudantes, pode exigir tutores para auxiliar o docente. Como esta realidade não é factível na maioria das escolas, principalmente nas públicas e de ensino médio, o professor talvez precise de alguns estudantes-chave para realizar essa função.

O modelo de Sala de Aula Invertida permite, ao ver dos autores, um estágio de transição entre o modelo de ensino tradicional, centrado no professor, para seu modelo pleno, onde as aulas presenciais seriam utilizadas somente para a realização de atividades e testes. Nesse estágio de transição, seria mostrada aos estudantes a importância de seu engajamento nas atividades prévias aos momentos presenciais, incluindo aí roteiros para avaliação.

\subsection{Plataformas utilizadas/sugeridas}

Andrade e Souza (2016) sugerem os seguintes ambientes virtuais/plataformas de ensino: Khan Academy, Knewton, Smarth Sparrow e Edmodo; ao passo que Schiehl e 
Gasparini (2016) não só sugerem, como também utilizam, o Google Sala de Aula ${ }^{3}$ e quizzes da Khan Academy.

\section{Indícios para delineamento do quadro adaptativo}

As plataformas utilizadas no estudo de Andrade e Souza (2016), com exceção da Khan Academy, ainda não têm grande aceitação no Brasil, principalmente porque ainda não estão adaptadas integralmente à Língua Portuguesa. Ainda que o professor se disponha a utilizá-las, julga-se que esta barreira é um fator demasiadamente impactante para sua total utilização pelos estudantes.

Por outro lado, o Google Sala de Aula é, atualmente, uma excelente ferramenta para o início de experiências de Ensino Híbrido, pois, além de gratuito, oferece ótimas oportunidades de interação entre estudantes e professor. Porém, falta-lhe ferramentas que possibilitem o trabalho compartilhado, como a criação de fóruns de discussão.

\subsection{Adaptação aos recursos tecnológicos}

Para Torres et al. (2014), o engajamento com a tecnologia e com o modelo de Ensino Híbrido se desenvolve com o passar do tempo. Uma pequena parcela tem uma prédisposição imediata, principalmente em relação ao modelo desse ensino.

Andrade e Souza (2016) sublinham que os recursos tecnológicos devem ser adequados tanto aos professores quanto aos alunos, de modo que possibilitem e facilitem o acesso do docente à produção dos estudantes, assim como dê suporte a esses últimos na produção de artefatos solicitados pelo professor.

\section{Indícios para delineamento do quadro adaptativo}

É possível observar que a análise feita na subseção anterior traz um complemento a esta. A plataforma de ensino utilizada e as tecnologias associadas impactarão bastante no fazer docente e na aprendizagem dos estudantes. Portanto, a decisão de quais suportes tecnológicos usar deve ser tomada de forma segura e baseada na prática.

O professor deve conhecer bem a plataforma onde exigirá acesso dos alunos; isso porque, além de ser o instrutor inicial para sua utilização, também precisará manipulá-la diversas vezes frente ao estudante, o que the demandará fluência. O professor não pode ser obstáculo para utilização da tecnologia escolhida por ele mesmo.

\subsection{Planejamento das atividades}

Andrade e Souza (2016) reforçam que, no planejamento do conteúdo online, deve constar a elaboração de um roteiro de um plano de estudo, ou roteiro de aprendizagem, indicando o material a ser utilizado e as atividades de aprendizagem a serem realizadas com autonomia e independência pelo aluno, preparando-o para o estágio da sala de aula.

No estudo de Schiehl e Gasparini (2016), os autores indicam que o planejamento do professor requer cuidado em todas as etapas. As atividades devem ser pensadas em diferentes níveis de dificuldades para estimular as capacidades dos alunos.

\footnotetext{
${ }^{3}$ O Google Sala de Aula é um ambiente virtual desenvolvido pela empresa de tecnologia Google e é uma das ferramentas disponíveis aos usuários do seu correio eletrônico. Para acessar a aplicação, basta ter uma conta associada ao domínio da empresa (@gmail.com, por exemplo).
} 
Indiscutivelmente, experiências de Ensino Híbrido exigem mais do professor. Mesmo sem entrar na discussão acerca da já constatada sobrecarga de trabalho de boa parcela dos professores brasileiros, partilha-se da ideia de que esse cenário é, sem dúvida, um dos principais - senão o principal - obstáculos que impedem a entrada de novas metodologias na sala de aula.

Entretanto, àqueles que se dispõem a enfrentar esse desafio, faz-se a indicação que a postura frente à preparação das aulas precisa mudar substancialmente. $O$ planejamento de um ciclo de estudo não deve ser realizado durante seu acontecimento, pois algumas etapas demandam bastante tempo para sua estruturação.

\subsection{O que as experiências de ensino relatadas nos estudos mostraram}

Torres et al. (2014) relatam que, com um semestre de antecedência, foi feita uma conscientização dos alunos e uma capacitação para os professores no desenvolvimento de conteúdos. Num segundo momento, realizou-se um treinamento com os alunos.

No texto de Andrade e Souza (2016), são descritos, de forma bastante minuciosa, vários detalhes das experiências relatadas no estudo. Como exemplo, três foram as experiências de RET:

(i) Na primeira, ocorreram 4 estações, com 75 minutos em cada. Em uma delas, um professor orientava parte do grupo por meio de uma aula expositiva; em outra, com o auxílio do tutor, os alunos realizavam o aprendizado online por meio de tablets; e, por fim, nas outras, desempenhavam atividades colaborativas ou individuais.

(ii) Em outra experiência, houve 3 estações, com 20 minutos em cada, sendo a primeira estação online.

(iii) $\mathrm{Na}$ última, foram 4 estações, com 5 minutos para cada, sendo as primeiras estações com a presença do professor. Nas duas seguintes, os alunos realizavam atividades individuais e colaborativas, e, na última estação, com caráter online, resolvendo exercícios solicitados pelo professor.

Nas experiências de Sala de Aula Invertida, Andrade e Souza (2016) descrevem a utilização da plataforma virtual Edmodo, mostrando que a escola disponibilizou ambiente e recursos para acesso ao material online e que, em sala, os alunos foram divididos em grupos de estudo, de forma que aqueles não cumpriam as tarefas de casa assistiam aos vídeos novamente.

No trabalho de Schiehl e Gasparini (2016), a experiência de Rotação por Estações de Trabalho aconteceu em 3 estações para 10 alunos em cada, com 15 minutos em cada estação. Numa delas, foi montado um estágio online; em outra, uma estação colaborativa; e, na outra, atividades individuais (podendo contar com o apoio do livro didático).

\section{Indícios para delineamento do quadro adaptativo}

A pulverização de procedimentos nos estudos citados é notória. Esse fato não impõe uma desconexão entre teoria e prática, mas revela o caráter adaptativo que a metodologia híbrida tem. Em cada estudo utilizado para comparação, há a ocorrência de experiências em níveis de ensino diferentes, o que traz, em consequência, formatações também bem distintas 
em termos de estrutura física e propensão discente à inserção nessa prática de ensino.

Um fato marcante, depreendido dos excertos acima, é o necessário envolvimento da escola no projeto de Ensino Híbrido em desenvolvimento, seja na disponibilização de infraestrutura necessária, seja na capacitação de seus agentes.

\subsection{Vantagens apontadas a partir das experiências realizadas}

Torres et al. (2014) relatam que as disciplinas a distância ocorreram no mesmo cronograma das presenciais, que os discentes perceberam a relevância de suas contribuições dentro dos ambientes colaborativos e que o desenvolvimento das disciplinas a distância possibilitou uma rede de colaboração entre os professores na discussão de técnicas pedagógicas.

Para Andrade e Souza (2016), o aumento das oportunidades de o professor trabalhar com grupos menores de estudantes, para que forneçam feedbacks em tempo hábil, é um fator de destaque. Também ressaltam a importância da criação de oportunidades para que os estudantes aprendam, de forma individual e colaborativa, por meio do acesso a diversos recursos tecnológicos - o que gera um significativo progresso em sua autonomia.

Segundo o texto de Schiehl e Gasparini (2016), por uma avaliação qualitativa, percebeu-se, antes mesmo do final do ano letivo, um maior engajamento dos estudantes durante as aulas, com atitudes mais colaborativas. A disposição organizada no modelo de Rotação por Estações possibilitou um maior contato entre professor e estudante, assim como a colaboração entre estes últimos.

\section{Indícios para delineamento do quadro adaptativo}

Os resultados relatados nos estudos reforçam os benefícios alcançados a partir da interação de seus sujeitos. A rede de estudos criada pelos estudantes na hora de resolver problemas e atividades, assim como também a de cooperação, que pode ser estabelecida por professores que, mesmo em disciplinas diferentes, utilizam a metodologia híbrida, por si só já se configuram como atrativos didáticos e profissionais que valem a pena sua experimentação.

\subsection{Sinais de alerta durante o andamento das experiências de Ensino Híbrido}

O estudo de Torres et al. (2014) traz importantes pontos para reflexão sobre as dificuldades com as quais, provavelmente, o professor se defrontará no decorrer nas atividades que resolver implantar. Na percepção dos autores, os profissionais e professores envolvidos indicam que o sucesso do projeto depende de se proporcionar uma estrutura adequada, da qualidade dos materiais utilizados no aprendizado e da excelência no diálogo entre professores e alunos, no sentido de fomentar o ensino-aprendizagem individual e em grupo, por meio da construção coletiva dos saberes. Um desafio foi mostrar aos estudantes que o conteúdo desenvolvido no ambiente virtual possuía a mesma qualidade de seu desenvolvimento em aula presencial.

Outro desafio foi estimular os alunos a assumirem a responsabilidade por seu aprendizado, já que ocorreram casos de insatisfação pela não adaptação à tecnologia e à modalidade de ensino. Àqueles com dificuldades na condução das atividades, foram marcados encontros presenciais para qualificá-los. Instigar colaboradores também se configura como um desafio, e, por isso, os autores expõem que a implementação de um 
modelo híbrido exige a estratégia de conseguir identificar professores predispostos às mudanças de comportamento e de prática profissional.

Ainda segundo Torres et al. (2014), o processo de implementação de uma experiência híbrida não se solidifica enquanto o modelo não estiver operando com uma qualidade de ensino estável - preferencialmente superior àquela experimentada nos modelos anteriores e for capaz de promover o desenvolvimento dos alunos como sujeitos ativos no processo de ensino-aprendizagem.

Andrade e Souza (2016) chamam a atenção para a necessária acessibilidade de todos os recursos pelos alunos.

\section{Indícios para delineamento do quadro adaptativo}

Estes pontos levantados, principalmente pelo estudo de Torres et al. (2014), reforçam outros já contemplados nas subseções anteriores. Como exemplo, pode-se citar o necessário envolvimento da escola no processo de sensibilização, suporte e implantação das experiências híbridas.

Ademais, frisa-se a citação dos autores contida no terceiro parágrafo desta subseção. Ela nos remete à ideia de que um modelo híbrido não se consolidará de imediato nem tampouco será adotado por professores e estudantes e professores facilmente. A solidificação de experiências ocorrerá quando bons resultados começarem a aparecer e a equipe de profissionais se envolver com a dedicação necessária.

\subsection{Quadro adaptativo: síntese dos indicadores}

As experiências relatadas nos estudos de Torres et al. (2014), Andrade e Souza (2016) e Schiehl e Gasparini (2016) serviram, como já mencionado, como suporte para propor um modelo que auxilie professores na implementação de estratégias metodológicas de Ensino Híbrido - caracterizado pelo que a literatura preconiza como sustentado. Dados os indicativos das sete subseções anteriores, registrar-se-á, abaixo, o delineamento proposto, o qual, ao final desta seção, será sintetizado num quadro adaptativo, permeável, portanto, a várias realidades de ensino.

a) Modelo a adotar: primeiros passos

A mudança de concepção na prática pedagógica de qualquer professor não parece aceitar rupturas bruscas. Não só o referencial teórico para o Ensino Híbrido oferece sugestões assim, mas a própria realidade vislumbrada impele isso. Assim sendo, ao professor que aceite o desafio de experienciar este modelo, sugere-se como primeiros passos o modelo da Sala de Aula Invertida. Gradativamente, já com situações exitosas deste modelo, abrir-seá naturalmente espaço para a opção da Rotação por Estações.

Começando pela Sala de Aula Invertida, recomenda-se também a construção de um tutorial de uso dos ambientes virtuais (ou plataformas digitais de ensino), de modo que o estudante possa aprender com ele em casa, não necessitando utilizar-se do tempo da sala de aula. Com essa familiarização precedente, a utilização da tecnologia em outros momentos dentro de sala, não só em experiências de Sala de Aula Invertida, mas também nas de Rotação por Estações, já não demandará treinamento, o que otimiza o tempo destinado à execução das atividades.

Este modelo inicial de Sala de Aula Invertida permite um estágio transitório, onde as 
primeiras aulas presenciais poderiam ser utilizadas para encorpar o conteúdo online, adicionando esclarecimentos que se fizerem necessários ao seu bom entendimento. Essa é uma alternativa, não uma condicionante. O professor, por óbvio, sentirá a necessidade ou não de sua implementação. Aos poucos, dentro de um cronograma particular do docente, 0 modelo poderia caminhar para sua plenitude, fazendo incidir sobre o cotidiano de estudos dos alunos a necessidade de preparação prévia em casa.

Dentro de uma etapa de avaliação - bimestre, trimestre, semestre ou até o próprio ano letivo - é possível que os dois modelos aconteçam concomitantemente, ou seja, a Sala de Aula Invertida não impede a Rotação por Estações, e vice-versa. Este último modelo, inclusive, permite que uma das estações de trabalho/estudo seja fora da sala de aula, possibilitando um modelo de Rotação por Estações incrementado com uma estação de Sala de Aula Invertida, o que seria a hibridização de dois modelos híbridos.

b) Ambientes virtuais de aprendizagem (AVA) ou plataformas digitais de ensino

A estação online necessária ao modelo de rotação ou o segundo espaço de estudo da Sala de Aula Invertida demandarão, inevitavelmente, um ambiente virtual para desenvolvimento de atividades. Os estudos tomados por referência sugerem algumas plataformas que não parecem ser as melhores opções para as primeiras experiências, como mencionado na subseção 4.2 .

Por outro lado, há de se destacar o Google Sala de Aula e a Khan Academy. Tratamse de dois objetos digitais diferentes: o primeiro configura-se como um ambiente virtual de aprendizagem, e o segundo, como uma plataforma online de ensino-aprendizagem, ou um objeto de aprendizagem, como sugerem Duarte e Calejon (2015) e Santos e Amaral (2012). Ambos, no entanto, trazem recursos gratuitos, bastante suficientes para o desenvolvimento de atividades híbridas.

Outro AVA de destaque no cenário de ensino a distância é o Modular Object-Oriented Dynamic Learning Environment (Moodle). Criado originalmente para suprir a demanda da educação a distância (EaD), o Moodle é hoje mundialmente reconhecido pela sua capacidade adaptativa e de oferecimento de ferramentas de interação e colaboratividade, tornando-se uma das referências nesse setor, não só por ser um software livre, mas por sua capacidade de responsividade, ou seja, de oferecer respostas rápidas e adequadas. No entanto, sua utilização depende de suporte tecnológico adequado na instituição que o abrigará, o que, num primeiro momento, pode demandar a necessidade de investimentos. Apesar disso, para aquelas instituições que pretendem investir no ensino híbrido, o Moodle se apresenta como uma alternativa bastante competitiva, devido ao seu custo-benefício.

c) Fluência tecnológica

O professor, enquanto mediador inicial do uso da tecnologia, deve estar preparado para esse papel. Não é necessário que ele se apresente como um especialista, um desenvolvedor, mas é importantíssima sua fluência na tecnologia que utilizará. Ainda que esta se solidifique com o tempo e com o uso, não é pertinente que o professor deixe transparecer aos estudantes que está no mesmo nível de conhecimento de utilização da tecnologia que eles. O domínio em um nível superior é requisito mínimo para o docente.

Se o professor for utilizar a edição de vídeos, o cuidado com a arte-finalização também merece destaque. Em nenhum momento, será exigida qualidade de cinema, mas um roteiro bem feito e recursos audiovisuais empregados com cuidado e parcimônia tornam-se 
essenciais.

d) Planejamento e execução das atividades

O planejamento de uma experiência de Ensino Híbrido é o cerne de sua execução. Se bem planejada, a chance de obter êxito é maior. Além disso, uma primeira experiência cria as condições de aprendizado para os próprios professores desenvolverem as próximas. Muitos materiais podem ser reutilizados ou adaptados, e, com o passar dos ciclos, o docente perceberá que vai precisar cada vez menos de tempo para o planejamento, o que não implica em supressão desta etapa.

É importante frisar que desenvolver conteúdo quase que concomitantemente à sua disponibilização aos estudantes não se mostra uma prática profissional ideal. Pela própria característica não linear do Ensino Híbrido, muitas vezes, alguns alunos terão condições de acessar conteúdos à frente daquilo que está sendo visto nas aulas presenciais, o que exige certa antecipação por parte do docente. Por isso, é necessário que o material a ser disponibilizado pelo professor seja sempre preparado com antecedência; mas sua disponibilização, no entanto, dependerá da rotina criada na ocasião.

As experiências relatadas nos estudos de Torres et al. (2014), Andrade e Souza (2016) e Schiehl e Gasparini (2016) somam-se na intenção de traçar um indicativo de utilização de metodologia híbrida. A comparação ora feita, portanto, não pretende acentuar as diferenças entre os textos, mas procura captar as lacunas de um para preencher as de outro, a fim de formar um cenário único. Da análise feita, pôde-se perceber que o conteúdo a ser abordado e o número de estudantes na sala ou nos grupos de estudos darão os indicadores de tempo, a quantidade de estações de trabalho (para o caso do modelo de Rotação por Estações), a quantidade de aulas destinadas a cada etapa de abordagem de conteúdos etc.

É importante ressaltar, também, que uma rede colaborativa de estudos para os alunos deve ser fomentada pelo professor dentro da sala de aula física e durante os momentos fora dela, seja online ou não. Os benefícios dessa interação tendem a incrementar o debate do que se está estudando, e, mesmo que alguns estudantes prefiram um modelo individualizado de aprendizagem, ao serem inseridos em ambientes colaborativos, podem despertar para 0 sentido da construção conjunta que, deles, muitas vezes será exigida fora do ambiente escolar. Neste sentido, Filipe e Orvalho (2004) já advertiam, à época de seu estudo, sobre a falta de competências colaborativas natas nos alunos envolvidos no relato que analisaram, o que demandou para eles - e também pode demandar nas experiências realizadas atualmente - o empreendimento de estratégias de superação dessa dificuldade.

No entanto, em experiências que contem com a divisão da sala em grupos, torna-se crucial dimensionar as atividades colaborativas ao tamanho do grupo, tendo em mente que, quanto maior o grupo, mais difícil será o exercício do debate e do consenso.

Finalizando, remete-se à subseção 4.7 e aos indícios já levantados na ocasião. Não haverá experiência exitosa sem o envolvimento da escola como um todo. Ainda que não estejam totalmente esclarecidas as dúvidas levantadas inicialmente, é papel do professor convencer os gestores, educadores e, dentro do possível, seus demais pares. O modelo híbrido precisa ser encarado como uma das acepções metodológicas da escola e, como tal, carecerá de suporte pedagógico-administrativo e técnico, quando necessário.

Apenas o trabalho de Andrade e Souza (2016) discorre mais densamente sobre influências do modelo híbrido na avaliação de aprendizagem. Pela complexidade do tema, ele 
não será abordado neste estudo, mas registra-se uma concordância com os autores quando ressaltam a importância de que os objetivos de cada estação (ou ambiente, no caso da Sala de Aula Invertida) estejam alinhados com os resultados de aprendizagem que o professor deseja alcançar e com o tipo de atividade proposta ali. O processo avaliativo não se mostra tão diferente daquele que as experiências de ensino tradicional já nos impõem, apresentandose igualmente difícil. No entanto, sem prejuízo do modo quantitativo, é preciso privilegiar aspectos qualitativos que levem em conta a participação em atividades em grupo, frequência de acesso e participação nas plataformas, qualidade nas respostas dadas nos vários ambientes de ensino etc.

Por fim, o quadro-síntese dos subsídios apontados anteriormente:

QUADRO 1: Síntese dos indicadores para implantação de experiências de Ensino Híbrido

\begin{tabular}{|c|c|}
\hline INDICADORES & SUGESTÕES \\
\hline $\begin{array}{l}\text { Modelo a } \\
\text { adotar }\end{array}$ & $\begin{array}{l}\text { - Comece por um modelo transitório de Sala de Aula Invertida; } \\
\text { - incremente aos poucos esta ideia até levá-la à plenitude dentro de um } \\
\text { mesmo ciclo (etapa) de ensino-avaliação; } \\
\text { - estenda a experiência ao modelo de Rotação por Estações a partir da } \\
\text { expertise acumulada ou se perceber que o modelo de Sala de Aula } \\
\text { Invertida não o atendeu completamente; } \\
\text { - avalie a possibilidade de juntar as modalidades criando uma estação } \\
\text { invertida numa das etapas da Rotação por Estações. }\end{array}$ \\
\hline $\begin{array}{c}\text { AVA ou } \\
\text { plataformas } \\
\text { digitais }\end{array}$ & $\begin{array}{l}\text { - A utilização de uma plataforma (ou ambiente virtual) de fácil manuseio é } \\
\text { importante num primeiro momento. Entretanto, não infira que as maiores } \\
\text { dificuldades estarão com seus estudantes; é provável que a capacidade de } \\
\text { adaptação deles seja maior que a dos docentes; } \\
\text { - o Google Sala de Aula é uma opção imediata e bastante otimizada para } \\
\text { primeiras experiências; } \\
\text { - outras opções podem ser avaliadas: redes sociais, sites ou blogs } \\
\text { particulares criados especificamente para isso etc. No entanto, é possível } \\
\text { que o nível de interação e colaboratividade, característica bastante } \\
\text { almejada, seja prejudicado; } \\
\text { - a implantação do Moodle, ou outro AVA semelhante, deve ser avaliada } \\
\text { junto à gestão da escola num médio prazo, principalmente se houver } \\
\text { adesão de outros professores à proposta de metodologia híbrida; } \\
\text { - a Khan Adademy é uma boa opção para as aulas de Matemática, mas sua } \\
\text { utilização não deve caminhar para a exclusividade. }\end{array}$ \\
\hline $\begin{array}{r}\text { Fluê } \\
\text { tecno }\end{array}$ & $\begin{array}{l}\text { - Garanta sua capacidade de utilização dos recursos tecnológicos, ainda } \\
\text { que ao nível de usuário; } \\
\text { - domine os principais recursos audiovisuais que resolver utilizar, ainda que } \\
\text { em nível de usuário; } \\
\text { - a depender do nível de envolvimento de outros professores, articule } \\
\text { momentos de capacitação entre todos, mesmo que em nível de usuário } \\
\text { para usuário; } \\
\text { - ofereça momentos para sensibilização dos estudantes para utilização das } \\
\text { novas mídias de aprendizagem, incluindo, neste tempo, se necessário, } \\
\text { capacitação para sua utilização. }\end{array}$ \\
\hline $\begin{array}{l}\text { Planejamento e } \\
\text { execução das }\end{array}$ & $\begin{array}{l}\text { - A experiência do Ensino Híbrido vai exigir muito mais do seu tempo de } \\
\text { planejamento! Isso, inicialmente, pode parecer muito pesado, mas, com o }\end{array}$ \\
\hline
\end{tabular}




\begin{tabular}{|c|c|}
\hline INDICADORES & SUGESTÕES \\
\hline atividades & $\begin{array}{l}\text { tempo e também com outras experiências, vai mostrar-se mais rotineiro; } \\
\text { - o conteúdo a ser abordado na etapa de ensino-avaliação e os objetivos } \\
\text { traçados para ela influenciam de tal maneira na configuração das atividades } \\
\text { que não se mostra factível tentar estabelecer um padrão de realização para } \\
\text { as etapas; } \\
\text { - em Matemática, iniciar por conteúdos ligados à Geometria, Trigonometria } \\
\text { e Álgebra Funcional, que têm maior aderência ao modelo híbrido devido aos } \\
\text { softwares dinâmicos disponíveis (o GeoGebra é um exemplo); } \\
\text { - o nível de ensino (fundamental, médio ou superior) e de autonomia } \\
\text { discente, além da própria quantidade de estudantes na sala ou nos grupos } \\
\text { de estudos, darão os indicadores de tempo, quantidade de estações de } \\
\text { trabalho (para o caso do modelo de Rotação por Estações), quantidade de } \\
\text { aulas destinadas a cada etapa de abordagem de conteúdos etc. } \\
\text { - construa e fomente uma rede colaborativa de estudos para os alunos a } \\
\text { partir do desenvolvimento de atividades, de pesquisas e de debates. Esta } \\
\text { tarefa é intrínseca à atividade docente no modelo híbrido, sem a qual sua } \\
\text { experiência estará incompleta; } \\
\text { - em experiências que contem com a divisão da sala em grupos, torna-se } \\
\text { crucial dimensionar as atividades colaborativas ao tamanho do grupo, tendo } \\
\text { em mente que, quanto maior o grupo, mais difícil tornar-se-á o exercício do } \\
\text { debate e do consenso; } \\
\text { - procure desenvolver atividades em conjunto com outros professores que } \\
\text { se interessam pelo tema; a rede de colaboração docente é tão importante } \\
\text { quanto a discente; } \\
\text { - sendo o modelo híbrido aceito como uma das acepções metodológicas da } \\
\text { escola, carecerá, para firmar-se como tal, de suporte pedagógico- } \\
\text { administrativo e técnico, quando necessário; } \\
\text { - sem prejuízo do modo quantitativo, há de se privilegiar aspectos } \\
\text { qualitativos que levem em conta a participação em atividades em grupo, } \\
\text { frequência de acesso e participação nas plataformas, qualidade nas } \\
\text { respostas dadas nos vários ambientes de ensino etc. }\end{array}$ \\
\hline
\end{tabular}

\section{Considerações finais}

A leitura dos diversos estudos referenciados reforça a percepção destes autores sobre as potencialidades das tecnologias para o ensino. Não se trata de vislumbrar uma revolução, descartando-se os métodos utilizados até hoje sem elas. O ensino tradicional não deve representar a obsolescência, pois ele funcionou até os dias atuais e fomos educados nele; mas estamos aqui para rediscuti-lo e incrementá-lo com a incorporação das funcionalidades positivas das tecnologias experimentadas atualmente.

Da leitura, análise e crítica dos estudos de Torres et al. (2014), Andrade e Souza (2016) e Shiehl e Gasparini (2016), pôde-se construir um quadro com indicativos objetivos para aqueles docentes interessados em aventurar-se nesse cenário convidativo, mas intimidador, num primeiro momento. A discussão teórica estabelecida desde a segunda seção mostra que as nuances do Ensino Híbrido permitem modelações próprias para a sua acomodação às diversas concepções de ensino, de metodologias, de disciplinas e de níveis de ensino. Além disso, por meio dos relatos das experiências citadas nos estudos, puderam- 
se captar elementos que impactam decisivamente no seu transcorrer, configurando-se como potenciais para o sucesso ou o fracasso de novas experiências. Assim, o Ensino Híbrido deve ser visto, em sua essência, como uma metodologia ativa prontamente acessível, adaptativa e inacabada.

É papel do professor realizar o convencimento de gestores, educadores e, dentro do possível, dos demais pares sobre a importância da discussão acerca da entrada de tecnologias no ensino. A experiência exitosa de uma instituição americana, narrada por Moskal, Dziubian e Hartman (2013), serve de exemplo para outras no Brasil a partir do momento que demonstra a importância do engajamento de uma equipe multiprofissional disposta a enfrentar desafios ao longo do tempo.

Concordando com Moran (2015a, p. 33), acredita-se que o Ensino Híbrido tem a capacidade de despertar motivações extrínsecas e intrínsecas nos estudantes: a "aprendizagem extrínseca é útil para criar hábitos, rotinas e procedimentos, sobretudo com crianças, mas, posteriormente, é mais importante que seja internalizada pelos próprios estudantes".

Portanto, cabe à classe docente interessada no assunto criar os ambientes para início da discussão sobre o tema dentro das escolas, ultrapassando as fronteiras das universidades. Para o ensino superior, há legislação que incentiva, já que a Portaria nํ⒋059, de 10 de dezembro de 2004, do Ministério da Educação (MEC), pode ser considerada como regulamentadora do processo de hibridização do ensino. Já para o ensino básico, tem-se muito incentivo governamental para iniciar este processo. Há, pois, ambiente para, pelo menos, iniciar o debate de possíveis experimentações.

\section{Agradecimentos}

Os autores agradecem à Coordenação de Aperfeiçoamento de Nível Superior CAPES pelo apoio financeiro dado ao convênio celebrado entre o IFMG e a Unicsul.

\section{Referências}

ANDRADE, M. do C. F. de; SOUZA, P. R. de; Modelos de rotação do ensino híbrido: estações de trabalho e sala de aula invertida. E-Tech: Tecnologias para Competitividade Industrial, Florianópolis, v. 9, n. 1, p. 3-16, jan./jun. 2016. Disponível em: <http:// etech.sc.senai.br/index.php/edicao01/article/view/773/425>. Acesso em: 18 jun. 2018.

BACICH, L.; TANZI NETO, A.; TREVISANI, F. de M. Ensino Híbrido: personalização e tecnologia na educação. In: __ (Org). Ensino Híbrido: personalização e tecnologia na educação. Porto Alegre: Penso, 2015. cap. 2, p. 47-54.

CASTRO, E. A.; COELHO, V.; SOARES, R.; SOUSA, L. K. S. de; PEQUENO, J. O. M.; MOREIRA, J. R. Ensino híbrido: desafio na contemporaneidade? Projeção e Docência, Brasília, v. 6, n. 2, p. 47-58, jul./dez. 2015. Disponível em: <http://revista.faculdade projecao.edu.br/index.php/Projecao3/article/view/563/505>. Acesso em: 18 jun. 2018.

CHRISTENSEN, C. M.; HORN, M. B.; STAKER, H. Ensino híbrido: uma inovação disruptiva? Uma introdução à teoria dos híbridos. [S. I: s. n], 2013. Disponível em: <https://s3.amazonaws.com/porvir/wp-content/uploads/2014/08/PT_Is-K-12-blended-learningdisruptive-Final.pdf>. Acesso em: 14 jun. 2018. 
COSTA, H. B. de A. Problematizando práticas de ensino e aprendizagem na plataforma Moodle: aproximações com a modalidade híbrida. EntreLínguas, Araraquara, v. 2, n. 2. p. 283-299, jul./dez. 2016. Disponível em: <https://periodicos.fclar.unesp.br/entrelinguas/ article/download/8773/5935>. Acesso em: 18 jun. 2018.

DUARTE, E. M.; CALEJON, L. M. C. Objetos de aprendizagem: uma análise da aprendizagem matemática e suas concepções tecnológicas. REnCiMa, São Paulo, v. 6, n. 1, p. 1-11, 2015. Disponível em: <http://revistapos.cruzeirodosul.edu.br/index.php/rencima/ article/view/1029/726>. Acesso em: 18 jun. 2018.

FILIPE, A. J. M.; ORVALHO, J. G. Blended Learning e Aprendizagem Colaborativa no Ensino Superior. In: Congresso Iberoamericano de Informática Educativa, 7, 2004, Monterrey. Anais eletrônicos... [S. I.]: 2004, p. 216-225. Disponível em: <http://www.ufrgs .br/niee/eventos/RIBIE/2004/comunicacao/com216-225.pdf>. Acesso em: 15 jun. 2018.

MORAN, J. M. Os novos espaços de atuação do professor com as tecnologias. Revista Diálogo Educacional, Curitiba, v. 4, n. 12, p. 13-21, maio/ago. 2004. Disponível em: $<$ http://www2.pucpr.br/reol/pb/index.php/dialogo?dd1=616\&dd99=view\&dd98=pb>. $\quad$ Acesso em: 18 jun. 2018.

MORAN, J. Educação híbrida: um conceito-chave para a educação, hoje. In: BACICH, L.; TANZI NETO, A.; TREVISANI, F. de M. (Org). Ensino Híbrido: personalização e tecnologia na educação. Porto Alegre: Penso, 2015a. cap. 1, p. 27-45.

MORAN, J. M. Mudando a educação com metodologias ativas. In: SOUZA, C. A. de; MORALES, O. E. T. (Org.). Convergências Midiáticas, Educação e Cidadania: aproximações jovens. Ponta Grossa: UEPG/PROEX, 2015b, 2 v. cap. 2, p. 15-33. (Coleção Mídias Contemporâneas). Disponível em: <http://www2.eca.usp.br/moran/wpcontent/uploads/2013/12/mudando_moran.pdf>. Acesso em: 18 jun. 2018.

MOSKAL, P.; DZIUBIAN, C.; HARTMAN, J. Blended learning: a dangerous idea? The Internet na Highter Education, [S. I.], v. 18, n. 3, p. 15-23. jul./set. 2013. Disponível em: <https://ac.els-cdn.com/S109675161200084X/1-s2.0-S109675161200084X-main.pdf?_tid $=$ bda25a15-48c8-4e00-9d03-3368c49f522b\&acdnat $=1529331325$

6ec26fff2da2228bd2a9dff118676912>. Acesso em: 18 jun. 2018.

ORGANIZAÇÃO DAS NAÇÕES UNIDAS PARA A EDUCAÇÃO, A CIÊNCIA E A CULTURA. O Futuro da aprendizagem móvel: implicações para planejadores e gestores de políticas. Brasília: UNESCO, 2014. $64 \quad$ p. $\quad$ Disponível em: <http:// unesdoc.unesco.org/images/0022/002280/228074por.pdf>. Acesso em: 18 jun. 2018.

PEÑA, M. de los D. J.; ALLEGRETTI, S. M. de M. Escola Híbrida: aprendizes imersivos. Revista Contemporaneidade, Educação e Tecnologia, São Paulo, v. 1, n. 2, abr. 2012. Disponível em: <https://revistacontemporaneidadeeducacaoetecnologia02.files.wordpress. com/2012/05/edutechi_puc20121.pdf>. Acesso em: 18 jun. 2018.

PRODANOV, C. C.; FREITAS, E. C. de. Metodologia do trabalho científico [recurso eletrônico]: métodos e técnicas da pesquisa e do trabalho acadêmico. 2. ed. Novo Hamburgo: Feevale, 2013. 276 p. Disponível em: <http://www.feevale.br/ Comum/midias/8807f05a-14d0-4d5b-b1ad-1538f3aef538/E-book\%20Metodologia\%20do\% 20Trabalho\%20Cientifico.pdf>. Acesso em: 18 jun. 2018.

SANTOS, M. E. K. L. dos; AMARAL, L. H. Avaliação de objetos virtuais de aprendizagem no ensino de Matemática. REnCiMa, São Paulo, v. 3, n. 2, p. 83-93, jul./dez. 2012. Disponível em: <http://revistapos.cruzeirodosul.edu.br/index.php/rencima/article/view/109/ 71>. Acesso em: 18 jun. 2018. 
SCHIEHL, E. P.; GASPARINI, I. Contribuições do Google Sala de Aula para o Ensino Híbrido. Revista Novas Tecnologias na Educação, Porto Alegre, v. 14, n. 2, jul./dez. 2016. Disponível em: <http://seer.ufrgs.br/index.php/renote/article/view/70684/40120>. Acesso em: 18 jun. 2018.

SILVA, E. L. da; MENEZES, E. M. Metodologia da pesquisa e elaboração de dissertação. 3. ed. rev. atual. Florianópolis: Laboratório de Ensino a Distância da UFSC, 2001. 121 p.

TORRES, K. A.; BORBA, E. L.; SOUSA, A. R. de; MARTINS, P. L.; Implantação da metodologia híbrida (blended learning) de educação numa instituição de ensino privada. In: Congresso Brasileiro de Ensino Superior a Distância, 11, 2014, Florianópolis. Anais eletrônicos... Florianópolis: NUTE-UFSC, 2014. p. 2354-2365. Disponível em: <http:// esud2014.nute.ufsc.br/anais-esud2014/files/pdf/128096.pdf>. Acesso em: 18 jun. 2018.

Submissão: 24/04/2018

Aceite: 25/06/2018 